\title{
"Un Diccionario no debe taparse los ojos ante la realidad". Metáforas sobre la lengua e ideología en el columnismo lingüístico académico ${ }^{1}$
}

\section{"A Dictionary should not close its eyes to reality". Metaphors on language and ideology within academic language columnism}

\author{
Carmen Marimón Llorca \\ Universidad de Alicante, Alicante, España \\ marimon@usa.es
}

ACCESO ABIERTO / OPEN ACCESS

Cita: Marimón Llorca, Carmen (2020). "Un Diccionario no debe taparse los ojos ante la realidad". Metáforas sobre la lengua e ideología en el columnismo lingüístico académico. Textos en Proceso, 6(2), pp. 70-90.

https://doi.org/10.17710/tep.2020.6. 2.6marimon

Editoras: Susana Guerrero Salazar y Carmen Marimón Llorca

Recibido: 02/11/2020

Aceptado: 20/11/2020

Conflicto de intereses: La autora ha declarado que no posee conflicto de intereses.

Copyright: @ Carmen Marimón Llorca. Esta obra está bajo licencia Creative Commons Reconocimiento 4.0

\section{Resumen}

El uso del lenguaje figurado supone un nivel alto de reflexividad sobre el lenguaje -de ahí su naturaleza metalingüística-, y opera siempre en un contexto social y lingüístico determinado. Este último aspecto es el que proporciona una dimensión ideológica al uso de determinados recursos. En efecto, distintos autores (Goatly, 2007; Bernel, 2007) han destacado la funcionalidad argumentativa de las metáforas en la medida en que proporcionan un escenario de comprensión -dominios de origen- que, de alguna manera, condicionan la forma en la que un determinado concepto va a ser recibido por los hablantes. El objetivo de este trabajo es analizar la funcionalidad discursiva de las metáforas metalingüísticas en un corpus de textos formado por columnas sobre la lengua escritas por autores académicos. En el trabajo se muestra qué papel desempeñan las metáforas como elementos argumentativos, hasta qué punto colaboran a construir una manera determinada de presentar el idioma, $\mathrm{y}$, en consecuencia, su contribución en la transmisión de un imaginario sobre la lengua y sobre la Academia que justifica la actividad institucional en la que se implican.

Palabras clave: discurso metalingüístico, lengua española, metáfora metalingüística, ideologías lingüísticas, lenguaje figurado.

\footnotetext{
${ }^{1}$ Este trabajo se enmarca en el Proyecto I+D+i PID2019-107265GB-I00 El columnismo lingüístico en la prensa española desde sus orígenes. Análisis multidimensional, caracterización y aplicaciones (METAPRES-COLING).
} 
Abstract

The use of figurative language presupposes a high level of reflexivity about language -hence its metalinguistic nature -and always operates in a given social and linguistic context. It is this last aspect that provides an ideological dimension to the use of certain resources. Indeed, different authors (Goatly, 2007; Bernel, 2007) have highlighted the argumentative functionality of metaphors insofar as they provide a scenario of understanding -domains of origin- which, in some way, condition the way in which a certain concept is to be received by speakers. The aim of this work is to analyse the discursive functionality of metalinguistic metaphors in a corpus of texts made up of columns about language written by academic authors. The work shows the role played by metaphors as argumentative elements, the extent to which they contribute to the construction of a specific way of presenting language and, consequently, their contribution to the transmission of an imaginary about language and about the Academy that justifies the institutional activity in which they are involved.

Keywords: Metalinguistic discourse, Spanish language, metalinguistic metaphor, linguistic ideologies, figurative language.

\section{Introducción}

Las figuras retóricas constituyen un catálogo organizado de posibilidades expresivas para ser utilizadas en relación con fines comunicativos. La metáfora, junto con la metonimia y la sinécdoque, es el núcleo indiscutido de los tropos y ha sido, con diferencia, el recurso retórico más estudiado y analizado a lo largo del tiempo, probablemente debido tanto a su complejidad como, paradójicamente, a la naturalidad con la que los hablantes la utilizan en su conversación cotidiana. La metáfora se benefició de la ampliación de la lingüística hacia los ámbitos pragmático-discursivos y del auge de la ciencia cognitiva, convirtiéndose en objeto de atención a partir, sobre todo, de la revolución radical que supuso el trabajo, ahora ya clásico, de Lakoff y Johnson (1980), en el que se redefinió la metáfora a partir de la experiencialidad y de las necesidades explicativas de los hablantes. Como hecho metapragmático, además, la metáfora es consecuencia del alto nivel de reflexividad sobre el propio lenguaje que poseen los hablantes (Caffi, 1994; ReyDebove, 1997; Reyes, 2002). En efecto, la naturaleza semiótica de la lengua hace posible que el hablante intervenga, explícita o implícitamente, en su discurso (Reyes, 2012, p 14). Y eso incluye seleccionar modos de expresión cuyo uso implica subjetividad y algún tipo valoración sobre su propio enunciado.

El estudio del lenguaje metafórico ha resultado muy fructífero para el análisis y comprensión de distintos tipos de discursos (Ciapuscio, 2013) -economía, medicina, publicidad, ciencia, etc.-; sin embargo, el estudio de la presencia de metáforas en los discursos sobre la lengua -las llamadas metáforas metalingüísticas- ha recibido una atención mucho más irregular. Hay trabajos que recogen y sistematizan la naturaleza y funcionalidad de las metáforas metalingüísticas referidos al inglés (Sweetser, 1992; Bernet, 2006; Underhill, 2011) y al francés (Ayres-Bennet, 2011; Fabré, 2012; Walsh-Cotelli, 2021). En cuanto al español, se han realizado aproximaciones puntuales -como las llevadas a cabo en su día en relación con el discurso metalingüístico- (Olza, 2011; Manero, 2005 o Fernández, 
2002). Por su parte Musci (s.a), Moreno Cabrera (2014) o Villa (2018), han estudiado la funcionalidad de la metáfora en relación con la construcción del discurso de la lingüística y de la representación del pensamiento lingüístico. Y Fernández Marrero (1999) analizó el uso de metáforas como recurso argumentativo en el discurso popular sobre la norma, pero falta para el español una propuesta sistematizadora como sí ha ocurrido, por ejemplo, para el inglés con los Proyectos METALUDE o el MetaNet Metaphor Wiki.

Este hecho contrasta con la familiaridad y la normalidad con la que se utilizan las metáforas metalingüísticas en textos divulgativos y de investigación sobre la lengua con la seguridad de que están totalmente asentadas en el idioma. Las batallas de la $\tilde{n}$ (Rafael del Moral), Palabras moribundas (Álex Grijelmo y Pilar García Mouton), El árbol de la lengua (Lola Pons), La lengua viva (Amando de Miguel) o España descubre el petróleo de la lengua (Fernando Vicente), son solo algunos ejemplos contemporáneos del uso de metáforas para hablar sobre la lengua en términos bélicos, somáticos o mercantiles. La asiduidad de su empleo alude a la existencia de un imaginario explicativo más o menos estereotipado que permite a los hablantes expresar actitudes hacia su lengua de manera experiencial y próxima a través de metáforas conceptuales convencionalizadas.

El objetivo de este trabajo es analizar la presencia y funcionalidad discursiva de las metáforas metalingüísticas en textos del columnismo lingüístico español. Para ello se han seleccionado tres columnas sobre la lengua escritas por miembros de la Academia y orientadas a exponer y justificar las nuevas incorporaciones -el nuevo vocabulario- que, periódicamente, se va aprobando en la Academia y que se incluirá en la siguiente edición del Diccionario. Son un total de 30 textos que, como señalamos en un trabajo anterior (Marimón, 2018)- constituyen un caso singular y delimitado dentro del género de las columnas sobre la lengua, tanto por su finalidad como por las condiciones de los emisores. Por lo que se refiere a los fines, estas columnas se caracterizan porque su actividad metalingüística no está dirigida a la emisión de juicios sobre el uso de la lengua, que es uno de los rasgos característicos del columnismo lingüístico (Marimón, 2019), sino a la justificación lingüística -y social- de las decisiones de la Corporación. En cuanto a los emisores, no se trata de hablantes más o menos expertos que opinan sobre la lengua, sino de académicos que hablan en nombre de la Academia, lo que confiere a las columnas naturaleza institucional. Nos interesa comprobar qué papel desempeñan las metáforas como elementos argumentativos; hasta qué punto colaboran a construir una manera determinada de presentar el idioma; $y$, en consecuencia, si contribuyen a transmitir un imaginario sobre la lengua y sobre la Academia que justifique la actividad institucional que transmiten.

Con el fin de proceder ordenadamente, el apartado siguiente está dedicado a delimitar el concepto "metáfora sobre la lengua" y a definir su funcionalidad como mecanismo metadiscursivo. En el apartado tres se describe el corpus y se justifica la pertinencia del columnismo lingüístico y su función reguladora sobre el lenguaje. En el apartado cuatro se aborda el análisis de las ocurrencias. Se identifican las principales metáforas metalingüísticas y se establecen las funcionalidades discursivas y argumentativas de estas. En las conclusiones se responde a las preguntas de investigación y se discute la aportación de estas columnas al lenguaje metafórico metalingüístico en español. 


\section{Las metáforas sobre la lengua}

A pesar de tener una larga tradición en occidente que se remonta a Quintiliano y Horacio (Ayres-Bennet, 2011, p. 239), las expresiones metafóricas metalingüísticas, como se ha señalado (Bernel, 2007, p. 268), han sido poco estudiadas. Los escasos trabajos que se han ocupado de ellas han mostrado que, por una parte, existen patrones que se repiten a lo largo del tiempo y en distintas lenguas, pero que, por otra, hay también metáforas conceptuales exclusivas o preferidas por una determinada comunidad lingüística. En efecto, desde Lakoff y Johnson (1980) sabemos que las metáforas -también las metalingüísticas- tienen una base cognitiva y experiencial y, en consecuencia, son universales; pero, al mismo tiempo, están culturalmente condicionadas, es decir, pertenecen a la visión del mundo de una sociedad, un colectivo o un individuo. Como el resto de los procesos metafóricos, las metáforas metalingüísticas seleccionan como dominios fuente o dominios de origen categorías comprensibles más o menos sencillas para explicar o hablar de categorías más complejas o abstractas, las llamadas dominios meta o dominios de destino (Soriano, 2012). Los dominios de origen tienen que ver con nuestras capacidades como seres en el mundo -el espacio, el tiempo, la orientación- y con nuestras facultades perceptuales -los sentidos- (Ungerer y Smith, 1996), lo que justifica que sea posible encontrar metáforas conceptuales comunes a muchas lenguas y sociedades. Así "el lenguaje es una planta" o "la lengua es una persona" son lugares comunes que dan lugar a expresiones metafóricas como "des mots qui prennent racine sur la langue" (francés) "una lengua cultivada" (español), "the life of language" (inglés) o "lo spirito della lingua" (italiano).

Pero la construcción de expresiones metafóricas también está estrechamente vinculada con nuestra existencia como seres sociales de manera que, como señala Villa (2018: 307), las metáforas organizan los conceptos, pero lo hacen guardando "coherencia con la cultura en la que se gestan". Somos nosotros, los individuos en contexto, quienes convertimos las palabras en discursos con significado que nos permiten comprender y construir a la vez una determinada visión del mundo. Para Underhill $(2012$, p. 8) las metáforas constituyen una de las posibles vías para comprender la manera en que creamos, mantenemos y transformamos distintas visiones del mundo a través del lenguaje (p.12). Y lo que resulta más significativo, todo esto ocurre a través de una herramienta -el lenguaje- cuya particularidad es, precisamente, como señala el propio Underhill (2011, p. 174), el estar metafóricamente construido: "the medium which allows us to construct metaphors is itself a metaphor-bound construct.".

En efecto las propias disciplinas que se han ocupado del estudio de la lengua han utilizado secularmente metáforas para proporcionar explicaciones sobre su funcionamiento. Así, por ejemplo, señala Villa (2018, p. 307), el comparativismo, evolucionismo y biologicismo de la primera mitad del XIX dio lugar al concepto metafórico "la lengua es un ser vivo/es un ser humano" que nace, evoluciona, tiene familias, sobrevive o muere. De esta manera, -añadimos nosotros- se consolidó una larga tradición de humanización de la lengua que tiene su origen en la imposibilidad de separar el lenguaje del acto físico y mental que conlleva.

A partir de Saussure, la metáfora conceptual dominante será "la lengua es un recipiente", que se despliega en otras como "la lengua como tesoro", "la lengua como diccionario" o "la lengua como gramática". Este tipo de metáforas -comenta Villa (2018, p. 308)-, están relacionadas con la idea de límite y más cercanas a lo social y mental que a lo biológico. En efecto, la concepción de la lengua como una 
"cosa", como un objeto que se puede poseer, intercambiar, transformar, conservar o adorar, que "está" en algún lugar -en un espacio social- y que tiene partes y propiedades ha proporcionado una gran cantidad de posibilidades de expresión metafórica, muchas de la cuales, como veremos, ocurren en este corpus.

Para Sweetser (1992, p. 712), la utilización de estas y otras metáforas para hablar de la lengua tiene que ver con la naturaleza a la vez concreta y abstracta, innata y cultural del propio lenguaje. En su opinión, tres aspectos del evento lingüístico se encuentran en la base de muchas metáforas metalingüísticas: la idea de que un intercambio comunicativo incluye un cara a cara; el hecho de que un intercambio hablado se entienda como un "encuentro entre mentes"; y la naturaleza social del discurso, que hará que se trasvasen las metáforas referidas a la actividad llevada al discurso mismo. A partir de estas tres ideas - continúa- se construyen y convencionalizan metáforas del tipo "Un intercambio lingüístico es un intercambio de objetos", "la interacción lingüística es un viaje compartido" y "el intercambio comunicativo es un combate". Las primeras tendrían origen en la direccionalidad y en la metáfora más amplia, "la mente es un cuerpo en el espacio", que permite hablar de la lengua con un vocabulario vinculado al movimiento sin que este realmente exista. La segunda procede de la metáfora "las actividades intencionales son viajes" que, a su vez, se despliega en otras como "la vida es un viaje", "el amor es un viaje" o "el pensamiento es un viaje". Si, señala Sweetser (1992, p. 716), el intercambio lingüístico es, en alguna medida, una forma de compartir el pensamiento, este puede expresarse metafóricamente también como un viaje. Finalmente, la idea de interacción como combate, lucha o juego cuyo objetivo es dominar al oponente tiene su correlato mental y lingüístico en las metáforas "las influencias son fuerzas" y "argumentar es un combate".

La selección de los dominios de origen para hablar de la lengua tiene que ver, pues, con la percepción por parte de los hablantes de algún tipo de relación experiencial -no necesariamente de semejanza- con el dominio de destino que permite iluminar o visibilizar un concepto, una actitud, un punto de vista o un tipo de relación con la lengua. Así, enunciados como: “¿Hasta dónde has llegado?" relativo a un texto o a una conversación, "Preferiría más riqueza léxica" o "tiene raíz griega" hablan de la lengua refiriéndose (a) a una experiencia espacio-temporal gracias a la cual el hablante puede dimensionar su experiencia verbal; (b) a la percepción de la riqueza como abundancia y ambas como un valor positivo -arriba, más-; y (c) a un elemento orgánico vegetal que permite establecer paralelismos entre las raíces físicas y los orígenes o el arraigo de algo.

\subsection{Las bases de datos de metáforas y las metáforas metalingüísticas}

En ninguna de las dos bases de datos que hemos consultado en las que se sistematizan las metáforas conceptuales -ambas para el inglés-, MetaNet Metaphor Wiki, del Internacional Computer Science Institute de la Universidad de Berckely y METALUDE, dirigido por Andrew Goatly y el LLE Project para la Lingnan University, aparecen las metáforas sobre la lengua de forma explícita, ni se hace referencia al lenguaje como dominio de destino. En ambos casos, lo referido a la lengua forma parte de categorías-meta más amplias como la comunicación y el pensamiento. En la imagen 1 se puede ver el Mapa raíz de analogías de METALUDE. 


\section{Map of Root Analogy}

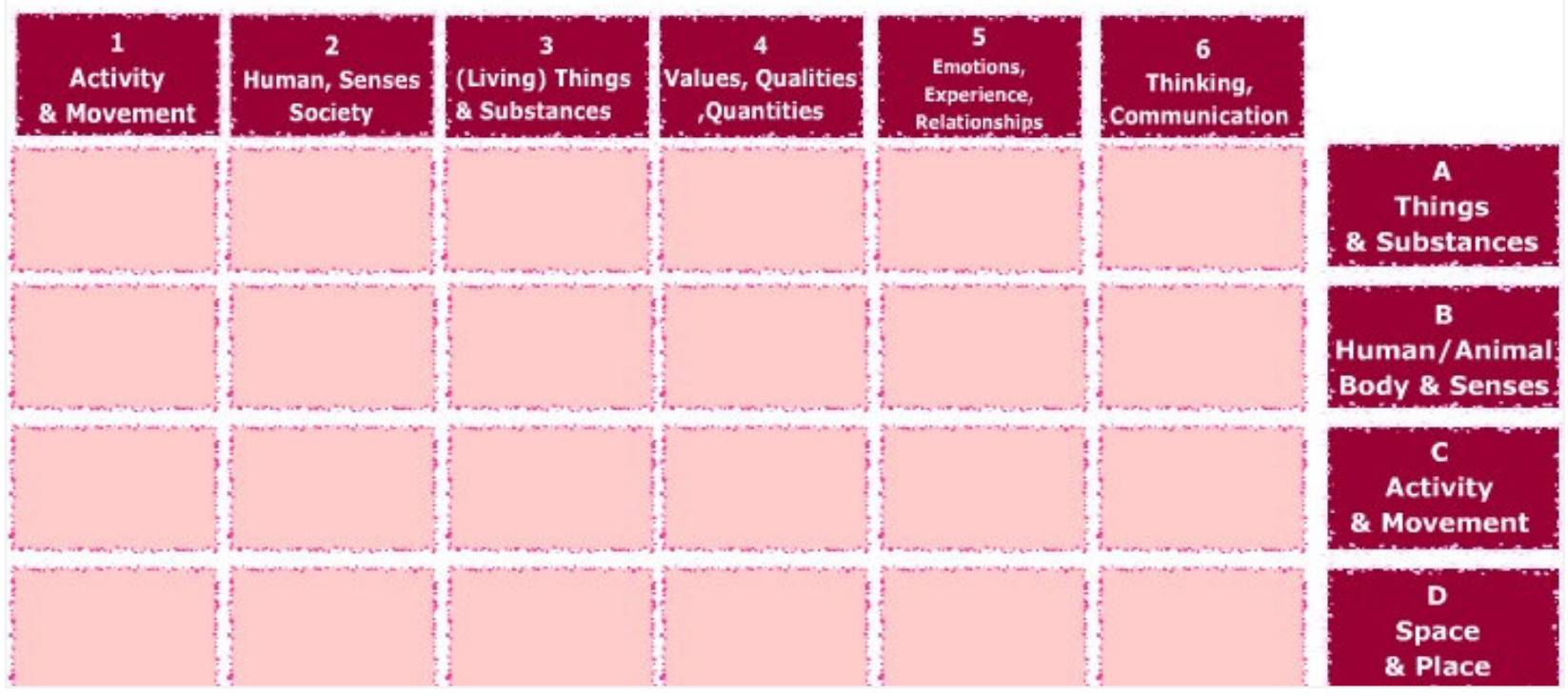

Fuente: METALUDE Copyright 2002-2005. Andrew Goatly \& LLE Project, Lingnan University.

Las casillas 1 al 6 corresponden a dominios de destino, que se cruzan con los dominios fuente representados en las casillas A-D. Cada intersección produce una cantidad de metáforas conceptuales; las relativas al lenguaje están incluidas en la categoría seis, "Pensamiento y comunicación".

En la tabla 1 hemos consignado las metáforas correspondientes a la categoría 6 distribuidas según los distintos dominios de destino. Hemos incluido, además de las metáforas metalingüísticas, aquellas que se refieren al pensamiento pero que tienen su correlato en la comunicación verbal.

Tabla 1. Metáforas metalingüísticas. Elaboración propia a partir de METALUDE. Copyright 2002-2005. Andrew Goatly \& LLE Project, Lingnan University

\begin{tabular}{|c|c|c|c|c|}
\hline \multirow{3}{*}{ 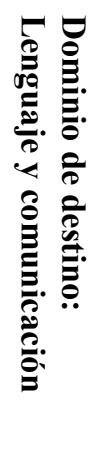 } & \multicolumn{4}{|c|}{ Dominio de origen } \\
\hline & A. Cosas y substancias & $\begin{array}{l}\text { B. Humano/Animal, } \\
\text { Cuerpo y Sentidos }\end{array}$ & $\begin{array}{l}\text { C. Actividad y } \\
\text { Movimiento }\end{array}$ & D. Espacio y lugar \\
\hline & $\begin{array}{l}\text { El texto es una } \\
\text { estructura. } \\
\text { Las ideas, los textos } \\
\text { son ropa [objetos] }\end{array}$ & $\begin{array}{l}\text { Las palabras/el } \\
\text { lenguaje es humano }\end{array}$ & $\begin{array}{l}\text { Discutir es luchar } \\
\text { Discutir/criticar es } \\
\text { atacar } \\
\text { La refutación es una } \\
\text { defensa } \\
\text { Los argumentos son } \\
\text { armas/municiones }\end{array}$ & $\begin{array}{l}\text { La certeza, la } \\
\text { comprensibilidad es abajo } \\
\text { [arriba/abajo] }\end{array}$ \\
\hline
\end{tabular}




\begin{tabular}{|c|c|c|c|c|}
\hline \multirow{4}{*}{ 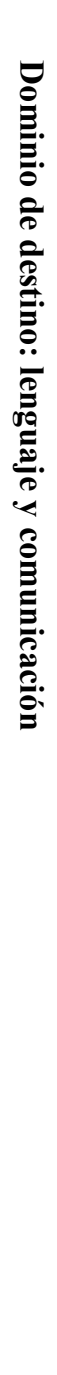 } & $\begin{array}{l}\text { El lenguaje es una } \\
\text { planta [plantas] }\end{array}$ & $\begin{array}{l}\text { Lo obvio es claro } \\
\text { Lo incomprensible no } \\
\text { es claro }\end{array}$ & $\begin{array}{l}\text { El lenguaje/el } \\
\text { pensamiento es un } \\
\text { viaje } \\
\text { La comunicación } \\
\text { verbal es } \\
\text { movimiento/viaje } \\
\text { La comunicación } \\
\text { verbal es un juego de } \\
\text { pelota. } \\
\text { Irrelevancia es } \\
\text { vagabundeo } \\
\text { Un discurso torpe es un } \\
\text { caminar torpe } \\
\text { El texto es un camino }\end{array}$ & $\begin{array}{l}\text { La comprensibilidad es } \\
\text { rectitud [dimensión, forma, } \\
\text { parte] }\end{array}$ \\
\hline & $\begin{array}{l}\text { La comunicación } \\
\text { verbal es una } \\
\text { transacción } \\
\text { [sustancias] }\end{array}$ & & & $\begin{array}{l}\text { El tópico, el asunto es un } \\
\text { lugar. } \\
\text { Diferencia es distancia } \\
\text { Similitud es proximidad } \\
\text { Lo correcto es un lugar en } \\
\text { un punto. } \\
\text { Elegir es separar. } \\
\text { La comunicación es } \\
\text { contacto. } \\
\text { El acuerdo es proximidad. } \\
\text { Las ideas/opiniones son un } \\
\text { lugar [lugar, distancia] }\end{array}$ \\
\hline & $\begin{array}{l}\text { Las palabras son } \\
\text { fluidos } \\
\text { [líquido] }\end{array}$ & & & \\
\hline & $\begin{array}{l}\text { Las palabras son } \\
\text { comida y bebida } \\
\text { La calidad del } \\
\text { lenguaje se puede } \\
\text { degustar [alimentos] }\end{array}$ & & & \\
\hline
\end{tabular}

La mayor parte de estas metáforas coinciden total o parcialmente con otros estudios en los que se tratan las metáforas metalingüísticas, como los de Fabré (2012), Underhill (2012) y Walsh y Cotelli (2021) para el francés, o Fernández Marrero para el español (1999). Fabré, por su parte, incide en su estudio llevado a cabo a partir de la antología de columnas de la prensa québécois de Cellar-Larosse (2010), en la importancia de las metáforas religiosas del tipo: "la lengua es un don de Dios" o" la lengua guardiana de la fe". Bernel (2007, p. 272-275), para el inglés, destaca la recurrencia de la metáfora conceptual "las reglas [ortográficas] son leyes" y hace notar la riqueza de la metáfora "la lengua es una persona" que permite atribuir a esta todas las características de lo humano. Por su parte, Fernández Marrero (1999, p. 180) subraya que, en español, para hablar del discurso normativo son frecuentes metáforas que desarrollan isotopías del tipo: lengua-guerra, lenguaderecho, lengua-religión, lengua-medicina, lengua-capital.

El discurso metalingüístico parece, pues, contar con un conjunto más o menos delimitado e identificable de construcciones metafóricas cuya existencia revela tanto la necesidad como la dificultad que los hablantes -cultos y profanosencuentran para explicar y definir actitudes hacia su propia lengua. 


\section{El corpus}

Como señalamos en la introducción, el corpus está compuesto por 30 columnas publicadas en la prensa por miembros de la Academia en las que dan a conocer las nuevas incorporaciones al Diccionario. En la tabla 2 se muestran los detalles del corpus:

Tabla 2. Corpus ${ }^{2}$

\begin{tabular}{|l|l|l|l|l|}
\hline Autor & Nombre de la columna & Medio & Fechas & $\mathbf{N}^{\mathbf{0}}$ de columnas \\
\hline Alonso Zamora Vicente & Sin nombre común & Revista de Occidente & $1970-1975$ & 9 \\
\hline Manuel Seco & La Academia y el lenguaje & ABC & $1983-1984$ & 10 \\
\hline Fernando Lázaro Carreter & Calle Felipe IV. Real Academia & ABC & $1986-1987$ & 11 \\
\hline
\end{tabular}

Se trata de una tarea -como estudiamos en otro lugar (Marimón, 2018)- que comenzó Julio Casares, secretario perpetuo de la Institución, al asumir la tarea de dar a conocer "públicamente y con cierta periodicidad, los acuerdos que va tomando [la Academia] en su ininterrumpida carrera de completar y perfeccionar el Diccionario oficial" (Julio Casares, $A B C, 15-03-1959)$. Con este objetivo publicó, entre 1959 y 1964, 32 columnas tituladas "La Academia española trabaja", la última de las cuales salió unos meses antes de su fallecimiento. A partir de esa fecha-el año 1964-, la Academia decide incluir en el Boletín de la Real Academia Española las novedades que esta va introduciendo en el léxico. Se trata de un hecho importante, pero sin duda, la repercusión mediática de esta actividad queda muy reducida. En 1971, Alonso Zamora Vicente -ahora también secretario perpetuodecide asumir la tarea de su antecesor, pero, esta vez, en una revista de alta divulgación, la Revista de Occidente. Allí publicará nueve artículos extensos, entre agosto de 1971 y enero de 1975, de aparición irregular, sin ningún título unificador, pero dedicados igualmente a dar cuenta de las nuevas palabras y significados que se incorporaban al Diccionario. La comunicación directa de la Academia con el público se retomará el 5 de julio de 1983, fecha en la Manuel Seco se ocupó de la tarea en el diario $A B C$ con la columna "La Academia y el Lenguaje", que se prolongó hasta el 15 de noviembre de 1984, con un total de diez artículos, no todos dedicados a comunicar las novedades. Finalmente, Fernando Lázaro Carreter, consumado columnista ya muy conocido por "El dardo en la palabra", asumió esa tarea con once colaboraciones entre 1986 y 1987.

\section{Las metáforas en el debate sobre la lengua}

Construir social y/o verbalmente una representación mental implica, entre otras cosas, activar marcos y esquemas cognitivos que permita a los individuos interpretar la realidad en una determinada dirección (van Dijk, 2008). En efecto, para autores como Goatly (2007, p. 30) "conventional conceptual metaphors construct and reproduce ideologies, and justify or reproduce certain behaviours" en la medida en que estas acaban conformando tópicos y lugares comunes, esquemas de argumentación generalizadores -argumentos basados en la mayoría o en creencias compartidas- que permiten presentar una idea o un punto de vista como un hecho indiscutiblemente asumido. Por su parte, las metáforas metalingüísticas no escapan

${ }^{2}$ Para citar el corpus se utilizarán las siguientes abreviaciones: Alonso Zamora Vicente (AZV, ROC), Manuel Seco (MS, AyL, $A B C$ ) y Fernando Lázaro Carreter (FLC, CFIV, $A B C$ ). 
a esta intencionalidad construida en la medida en que, muchas de ellas, proceden de estructuras metafóricas convencionalizadas y, por lo tanto, son entendidas como "parte de la manera natural de un grupo o comunidad de entender y pensar un dominio conceptual" (Santibáñez, 2008, p. 249). Metáforas orientacionales del tipo ARRIBA/ABAJO, DENTRO/FUERA, DELANTE/DETRÁS, PROFUNDO/SUPERFICIAL, CENTRAL/PERIFÉRICO con su correspondiente atribución valorativa BUENO/MALO tienen su trasunto en metáforas metalingüísticas. Lo mismo ocurre con las metáforas ontológicas que tienen como dominio de origen OBJETOS, RECIPIENTES O SUSTANCIAS, como hemos visto en la tabla 1 del apartado anterior. En todos los casos, estas metáforas contribuyen, como señala Bernel (2007, p. 268), a condicionar la forma de percibir el dominio de destino y eso ya es, añadimos nosotros, una forma de orientar ideológicamente una determinada visión de la lengua.

La finalidad divulgadora de las columnas académicas hace necesario que sus autores se expresen en un lenguaje cercano y comprensible para sus lectores, un público amplio y con distintos grados de conocimiento sobre la lengua. Las metáforas ofrecen la posibilidad de, mediante imágenes vinculadas a ámbitos de conocimiento próximos a la vida cotidiana, acercar a los lectores tanto a conceptos abstractos y especializados -los propios de las disciplinas lingüísticas-, como a actividades poco comunes -decidir sobre si una palabra merece o no estar en el Diccionario-. Desde este punto de vista, hemos organizado las metáforas metalingüísticas en dos grandes grupos:

(a) aquellas que sirven para hablar del idioma; y

(b) aquellas que se utilizan para transmitir una imagen de la actividad académica.

En el primer caso se encuentran las "metáforas sobre la lengua" en el sentido más estricto de la palabra. Tienen que ver con la necesidad de hacer comprensibles aspectos de la naturaleza del idioma, particularmente de las palabras, que son el objeto de estudio y la razón de ser de los Diccionarios. En el segundo grupo hemos incluido las metáforas de las que se valen los columnistas para hablar del trabajo académico. Son las que denominaremos "metáforas sobre la gestión de la lengua" pues a través de ellas se muestra el tipo de actividad, los objetivos y la trascendencia del trabajo institucional. Como es de esperar, unas y otras están estrechamente relacionadas, - una concepción de la lengua implica una determinada intervención sobre ella- $y$, aunque seleccionan diferentes dominios de origen, hay vínculos que los unen coherentemente.

Adelantamos, por otra parte, que no se observan grandes diferencias entre los columnistas analizados respecto a la selección de dominios de origen para construir sus metáforas, aunque sí hay diversidad en el peso que se les otorga, en la frecuencia de su uso y en el nivel de creatividad para construir la imagen metafórica -lo que constituye finalmente el estilo personal de cada autor-.

\subsection{Metáforas sobre la lengua/las palabras}

La tabla 3 muestra la preferencia de los columnistas por tres dominios de origen para hablar de la lengua/las palabras: el biológico, el objetual y el locativo. En el primer caso (4.1.1) se recurre a la corporeidad y a la humanidad para dotar de propiedades a las palabras. Se trata de metáforas estructurales que permiten un alto grado de concreción; el segundo grupo (4.1.2) está formado por metáforas ontológicas que asimilan la lengua/las palabras a algún tipo de sustancia o materia 
haciendo posible su manejo; finalmente, el tercer grupo (4.1.3) lo forman metáforas orientacionales y ontológicas con una fuerte carga valorativa. Son todas ellas metáforas cuyo objetivo es explicar hechos del lenguaje a través de la identificación (Musci, s.a.) del objeto de conocimiento con referentes -propiedades o materiaspróximos al hablante. La semejanza que hace posible esa identificación clarificadora no es previa a la metáfora - una palabra no "se parece" a un ser vivo-, sino que se construye a través de ella -se identifica el hecho de que una palabra empiece o deje de usarse con su nacimiento y/o su muerte-. El hecho, por otra parte, de que el lenguaje sea un rasgo específicamente humano y que deba su existencia a la existencia física del individuo -pensamiento, articulación, voz-; pero que exista también fuera de él -como texto, como discurso en cualquiera de sus posibles formas, como objeto por tanto-, propicia el uso de estos dominios fuente, los convencionaliza y acaba, en realidad, en un listado de lugares comunes para hablar del lenguaje del que parece difícil escapar.

Tabla 3. Tipo de metáforas sobre la lengua

\begin{tabular}{|l|l|}
\hline Tipo de metáfora & Ocurrencias \\
\hline La lengua/las palabras son seres vivos & 21 \\
\hline La lengua/las palabras tienen una trayectoria vital & 16 \\
\hline La lengua/ las palabras son seres sociales & 17 \\
\hline La lengua/las palabras tienen familia & 22 \\
\hline La lengua/las palabras están movimiento & 22 \\
\hline La lengua/las palabras son objetos manejables & 23 \\
\hline La lengua/las palabras son objetos de valor & 19 \\
\hline La lengua/las palabras ocupan un espacio [con límites] & 23 \\
\hline Número total de ocurrencias & 174 \\
\hline
\end{tabular}

\subsubsection{La carnalidad de la lengua: las palabras están vivas}

Las metáforas personificadoras $\mathrm{y}$, en un sentido más amplio, las que permiten dotar de vida a la lengua son, como hemos señalado, particularmente productivas y fecundas. Hablar de la lengua como algo viviente y existente, con propiedades biológicas y capacidad de decisión proporciona a los miembros de la Académica un campo de posibilidades expresivas familiar, concreto y amplio al tiempo que convencionalizado y, por tanto, delimitado y fácil de manejar. Las palabras y las acepciones, como cualquier ser vivo, nacen (1), viven (2), mueren (3) y (4), evolucionan (5), se desarrollan (6) o tienen edad (7):

1) será incluido como acepción nacida, por extensión (AZV, ROC).

2) y hoy se conserva perfectamente vivo en el léxico (MS, AyL, $A B C$ ).

3) se trata de un vocablo que murió repentinamente (FLC, CFIV, $A B C$ ).

4) las otras dos tampoco subsisten (FLC, CFIV, $A B C$ ).

5) el hablar de la edad de una palabra (MS, AyL, $A B C$ ).

6) En Francia desarrolló una nueva acepción (FLC, CFIV, $A B C$ ).

7) reconoces que la lengua debe evolucionar según las necesidades de los hablantes (FLC, CFIV, $A B C$ ). 
Explicar la lengua en términos biológicos permite justificar los procesos de cambio que se dan en el vocabulario sin necesidad de referencias a la morfología o a la fonética históricas. De naturaleza biológica pero también social, es la metáfora "la lengua tiene familia", un dominio de origen de larga tradición con el que se materializan las relaciones que se dan en el seno de la lengua. La metáfora de la familia se extiende hacia lo humano, como vemos en los ejemplos 8-15 en los que se establecen parentescos, genealogías, avecinamientos, linajes o filiaciones entre las lenguas:

8) se percibe un claro parentesco, una soterraña cercanía semántica (AZV, ROC).

9) el árbol genealógico de nuestra lexicografía (MS, AyL, $A B C$ ).

10) al adjetivo monovalente y a sus cuatro hermanos (MS, AyL, $A B C$ ).

11) y se añaden nuevos miembros [...] a la familia léxica (MS, AyL, $A B C$ ).

12) Se aseguraba que descendia del latín (FLC, CFIV, $A B C$ ).

13) Este vocablo no urgía para ser avecindado (FLC, CFIV, $A B C$ ).

14) Se ha procedido a la debida filiación de tal vocablo, pariente próximo del castellano pago (FLC, CFIV, $A B C$ ).

15) Enmascarando su linaje heleno (FLC, CFIV, $A B C$ ).

La capacidad simplificadora de este tipo de metáforas es evidente en el fragmento de Zamora Vicente (16) que recurre a dicho recurso para señalar la complejidad de la palabra "malandrín":

16) esa vocecita se la hacía proceder de muy lejano origen y a través de muy complejas encrucijadas (AZV, ROC).

La necesidad de vincular esos cambios con los contextos en los que ocurren es, probablemente, lo que lleva la metáfora personificadora un paso más lejos hasta "las lenguas son seres sociales". Con esta metáfora, las palabras, más allá de estar vivas o emparentadas, son entes civiles de manera que su existencia está legitimada -o no- por una autoridad que expende documentación -algo que, como se verá más adelante, las metáforas sobre la gestión académica de la lengua refuerza contundentemente-. En los ejemplos siguientes (17-21) las palabras son portadoras de certificados, tienen derechos, viven conforme a leyes:

17) Estos extranjerismos van entrando, entrando, hasta que llega un día que son tan connaturales y usuales que ya nadie piensa en su lejano origen, con sus documentos, su pasaporte, su peaje (AZV, ROC).

18) esas formas habian llegado al diccionario de manera irregular, desnivelando la ordenación y simetría rigurosas del diccionario $(\mathrm{AZV}, R O C)$.

19) podrán presentar un certificado de nacimiento, una fe de vida o carta de trabajo, según los gustos (AZV, ROC).

20) Ya tienen sitio con pleno derecho (AZV, ROC).

21) palabra que ahora ha registrado la Academia, más para darle sepulcro que fe de vida (FLC, CFIV, $A B C$ ). 
El mundo del léxico y de la lengua por extensión parece, así, un espacio reglamentado y legalizado, lo que proporciona un marco de seguridad explicativa tanto a los autores como a los hablantes a quienes van dirigidos estos textos. Manuel Seco supo sintetizar con claridad y sentido del humor está condición humana y social de la lengua:

las palabras tienen infancia, juventud, madurez, ancianidad. Igual que las personas, las palabras nacen y mueren. Las hay que tienen una vida efímera, y las hay que disfrutan de una longevidad patriarcal. Muchas conservan entero su vigor durante siglos; otras muchas arrastran, también durante siglos, una penosa decadencia en que casi nadie se acuerda de ellas. Cuando una palabra muere, cuando ya ningún hablante se sirve de ella, no hay quien se preocupe de extender su certificado de defunción: su cuerpo sin alma sigue indefinidamente ocupando su casilla, codeándose con las vivas, en ese registro civil del léxico que es el diccionario. (MS, AyL, $A B C$ ).

Finalmente, las metáforas vivificadoras se concretan en "la vida de la lengua es un viaje". Metafóricamente, el movimiento está ligado a la vida, a la acción, al pensamiento y, por extensión, como se vio en la tabla 2, a la comunicación y al lenguaje. En los textos del corpus, los desplazamientos están ligados a la idea de cambio en el seno de la lengua. Así, las palabras circulan (22-23), fluyen (24), recorren un camino (25-26), pasan de una lengua a otra (27), saltan (28), se desplazan (29), etc.

22) Este vocablo por lo limitado de su circulación (AZV, ROC).

23) La vida actual, como venimos destacando de continuo, nos ha puesto en circulación una serie de palabras (FLC, CFIV, ABC).

24) Es necesario estar atentos al fluir del idioma y ayudar todos un poquito.(AZV, ROC).

25) Se abre camino aunque sea a paso de procesión.(FLC, CFIV, ABC).

26) En ese camino del neologismo de sentido (AZV, ROC).

27) Del francés, ya atestiguado en el siglo XIV, ese valor pasó al español (AZV, ROC).

28) Qué animación cuando empiezan a saltar sobre el tapete verde vocablos familiares (FLC, CFIV, ABC).

29) las lenguas son hervideros de impulsos, desplazamientos, innovaciones, a pesar de la apariencia de inmovilidad (MS, AyL, ABC).

Son muy numerosas las ocurrencias que visualizan a las palabras haciendo un recorrido, trasmitiendo con ello la idea de que el lenguaje es una entidad en constante proceso. Frente a esto, el inmovilismo se asimila a la extinción -"Las únicas lenguas estables son las muertas"-. Se presentan, así, los autores académicos alejados de las posiciones de los puristas que "sordos a la realidad del uso, han obstruido el paso a un vocablo". Su tarea sobre la lengua, pues, es, sí, de regulación y de control, como se verá, pero "no para estorbar su progreso -aclara Lázaro Carreter- sino para impedir los descarríos y el deterioro".

\subsubsection{Los dominios físicos de la lengua: las palabras como objetos}

La identificación de la lengua con algún tipo de elemento material tiene en el corpus dos manifestaciones metafóricas distintas. Un grupo de metáforas sirve para 
presentar a la lengua y, en concreto, al léxico, como objetos flexibles y manejables y por lo tanto, susceptibles a la manipulación y la adaptación. Esto se manifiesta, por ejemplo, en las ideas del "ensanchamiento" (30) para aludir a la ampliación de significados, a su capacidad expansiva (31) o de acomodación (32); pero también contrariamente- en la representación de la lengua como un ente compacto (33) y no siempre fácil de amoldar (34). Se refiere en este último caso Lázaro Carreter a la adaptación de extranjerismos como "esnob" o "esmoquin" que un día fueron extranjerismos crudos pero que acabaron entrando en un molde fonético y gráfico:

30) ensanchamiento del sentido original (AZV, ROC).

31) Pacificada su denominación y extendida al empleo común (FLC, CFIV, $A B C$ ).

32) la acomodación de la palabra a los moldes gráficos, fonológicos y morfológicos del idioma (MS, AyL, $A B C$ ).

33) en este paquete de palabras (MS, AyL, $A B C$ ).

34) se les forzó a entrar en un molde fonético y gráfico (FLC, CFIV, $A B C$ ).

Otro grupo más numeroso desarrolla una metáfora metalingüística de gran tradición: "la lengua es un objeto precioso". Se trata de una metáfora que sobrepasa los límites de lo puramente estético, como apunta Fabré (2012: 207), para extenderse hacia una estética de corte nacionalista que, en el caso del español, tiene que ver con el concepto de unidad de la lengua con connotaciones panhispánicas, como se ve en 35-40:

35) La gran herencia $[\ldots]$ es nuestra lengua (AZV, ROC).

36) no perder la inmensa riqueza de pertenecer a una gran comunidad lingüística (MS, AyL, $A B C)$.

37) cómo el tesoro de nuestra unidad idiomática, por sólido que sea, está expuesto a agentes corrosivos que es necesario contrarrestar (MS, AyL, $A B C$ ).

38) hemos de cuidarla como la mejor hacienda, el pegujal más acariciado y mimado $(\mathrm{AZV}, R O C)$.

39) se enriquece con su actual significado (FLC, CFIV, $A B C$ ).

40) Como vemos, el diccionario se enriquece a costa de la vida (AZV, ROC).

Las metáforas referidas a la riqueza tienen una base orientacional según la cual la riqueza $-\mathrm{y}$ sus manifestaciones, como los tesoros- se asimila a los valores positivos de arriba/alto. Aplicados a la lengua, la convierten en un objeto digno de ser cuidado, conservado y protegido por todos, pero en particular, por quienes tienen acceso directo a él. Se trata de una metáfora con un espectro significativo amplio que está estrechamente ligada a otras como "la gestión de la lengua es una actividad higiénica" -todo lo valioso debe mantener su pureza-, o "la gestión de la lengua es una actividad civil" -lo valioso es gestionado por quien ejerce el poder-.

\subsubsection{Los límites de la lengua: las palabras y el espacio}

La metáfora locativa, que, habitualmente, sirve para reforzar la concepción objetualestática de la lengua (Marimón 2021), se utiliza en este caso para delimitar el 
espacio "de confort" de las palabras, su legítimo hogar, el sitio al que pertenecen, que no es otro que el Diccionario. Los ejemplos 41-46 lo muestran a través de distintas expresiones:

41) Entresaco solamente aquéllas que pueden, por una u otra razón, llamar más poderosamente la atención $(\mathrm{AZV}, R O C)$.

42) deja en una zona penumbrosa las voces aprobadas (AZV, ROC).

43) un término español que ocupe el lugar del extranjero (MS, AyL, $A B C$ ).

44) Ya ocupaba su nicho en el diccionario el vampiro (FLC, CFIV, $A B C$ ).

45) está, al menos en un noventa por ciento, dentro de las páginas de los diccionarios (MS, AyL, $A B C$ ).

46) Son muchas las voces ya plenamente instaladas (FLC, CFIV, $A B C$ ).

La evaluación positiva del "dentro" contrasta con la valoración negativa de lo que está fuera -"extramuros" (47), "desterrado" (48)-. Se trata de metáforas valorativas que reproducen el esquema ideológico dentro-bueno-nosotros/fueramalo-ellos (49) que es utilizado por los columnistas para establecer los límites de la pertenencia en relación con el vocabulario y que, habitualmente, están relacionados con los extranjerismos:

47) Palabras que acampan extramuros (FLC, CFIV, $A B C$ ).

48) Si desterrásemos de nuestro léxico todo lo que hemos tomado de otras lenguas (FLC, CFIV, $A B C$ ).

49) Vocablos ajenos que andan revueltos con los nuestros (FLC, CFIV, $A B C$ ).

\subsection{Metáforas sobre la gestión de la lengua}

La filiación institucional de los tres columnistas y, sobre todo, el propósito de su publicación coloca en primer plano la actividad académica. Para poder "hablar sobre la lengua" -que es la finalidad habitual de este tipo de colaboraciones periodísticas-, se hace necesario, en este caso, "hablar sobre cómo se gestiona la lengua", que es lo que da sentido a la institución. Si unas palabras son aceptadas o unos significados ampliados o restringidos, es, precisamente, porque la Academia tiene el poder, la legitimidad y la posibilidad de hacerlo. Las metáforas conceptuales encontradas en el corpus se refieren a dos grandes ámbitos de poder: el civil (4.2.1) y el religioso (4.2.2), tal y como se puede observar en la tabla 4. En el primer caso, las metáforas encuentran sus dominios de origen en la actividad legislativa, "la gestión de la lengua es una actividad civil" y en las disputas que conlleva "la gestión de la lengua es una actividad bélica"; en el segundo, las metáforas se construyen sobre una concepción sacralizada de la lengua, "la gestión de la lengua es una actividad religiosa" y de quienes tienen el deber de mantener su integridad, "la gestión de la lengua es una actividad higiénica". Un tercer ámbito, el de la naturaleza (4.2.3.), utiliza como dominio fuente el ciclo vegetal para explicar metafóricamente los procesos de maduración de las palabras (valga la metáfora). 
Tabla 4. Metáforas sobre la gestión de la lengua

\begin{tabular}{|l|l|}
\hline Tipo de metáfora & Ocurrencias \\
\hline La gestión de la lengua es una actividad civil & 70 \\
\hline La gestión de la lengua es una actividad bélica & 29 \\
\hline La gestión de la lengua es una actividad religiosa & 23 \\
\hline La gestión de la lengua es una actividad higiénica & 23 \\
\hline La gestión de la lengua es una actividad agrícola & 9 \\
\hline Número total de ocurrencias & 316 \\
\hline
\end{tabular}

\subsubsection{El ejercicio del poder sobre la lengua (I). El estatus civil de la actividad académica: registrar y batallar}

Como señala José del Valle (2011:486) "lengua y poder -esa pareja inseparablerecorren tomadas de la mano la historia toda de la humanidad". En efecto, la lengua durante el franquismo -época coetánea (Zamora Vicente) e inmediatamente anterior (Seco y Lázaro Carreter) a los años en los que escriben los tres columnistas-- había sido uno de los instrumentos de reafirmación ideológica. La actitud centrípeta y beligerante contra cualquier influencia externa dio lugar a posturas puristas y conservadoras respecto a la lengua; y la censura, a su vez, propició una retórica del poder pomposa y muy limitada expresivamente. A partir de la segunda mitad de los años setenta con la muerte de Franco y la aprobación de la Constitución, la sociedad española da un vuelco y, con ella, los hábitos de comunicación. El fin de la censura supone el gran momento de los medios de comunicación que, ahora sí, pueden usar la lengua sin limitaciones ni cortapisas. La apertura al exterior, por su parte, trajo un aluvión de novedades no solo materiales, sino ideológicas, intelectuales y sociales que requerían modos de expresión completamente renovados. En estas circunstancias, la Academia se ve en el dilema de tener que abrir las puertas del diccionario al español moderno. "La lengua -afirma Zamora Vicente- es siempre espejo de la realidad social en que se habla, y resulta, bien observada, su mejor exponente"; y desde esa posición cercana al habla real, pero sin perder de vista su papel regulador, la Academia va a actuar. En los textos de los columnistas encontramos metáforas que dan cuenta del poder que la institución ejerce sobre la lengua (50-55) y de la naturaleza de su tarea: vigilar (56), someter a normas (57), ordenar y fijar (58):

50) Psicodélico va a entrar, mejor dicho, ya está autorizada (AZV, ROC).

51) Ya está admitida, sancionada totalmente (AZV, ROC).

52) la aprobación de las enmiendas y adiciones (MS, AyL, $A B C$ ).

53) Y para terminar hoy, citaré una especie de espaldarazo que el Diccionario oficial va a dar al humor negro (AZV, ROC).

54) No existe, no está admitida (MS, AyL, $A B C$ ).

55) Las acepciones ya consignadas (FLC, CFIV, $A B C$ ).

56) [de los americanismos] será más vigilada y reglamentada su inclusión (AZV, ROC).

57) Hay que someter a las normas del idioma todo lo que no sea patrimonial (AZV, $R O C)$.

58) Se reordenan y fijan sus actuales sentidos (FLC, CFIV, $A B C$ ). 
La utilización como dominio de origen de la actividad jurídico-administrativa para hablar de la actividad sobre la lengua está completamente naturalizada: realizar "adiciones" y "enmiendas" o bien "registrar", "inventariar", "consignar", "reformar", "rectificar" y "corregir" construyen un imaginario normativo sobre la gestión de la lengua que remite a la legalidad, el derecho y la administración y sitúa, en consecuencia, la actividad académica en línea con los cuerpos legislativos del Estado (aunque realmente no lo sea).

Ligado, precisamente, a la administración del poder civil, está la posibilidad del litigio. Las disputas en torno a la lengua se expresan a través de metáforas estructurales que tienen sus dominios fuente en fenómenos sociales y políticos tan concretos como las guerras. La creación de un imaginario bélico alrededor de la lengua está ligado a la tradición purista y sitúa el debate público sobre la lengua en términos, como señala Bermel (2006: 283) de ganadores y perdedores, de quienes atacan y de quienes defienden determinados valores del idioma idiosincráticos e irrenunciables que se consideran en peligro o agredidos por alguna fuerza desestabilizadora. Los columnistas académicos no quieren situarse en este eje e incluso Seco se hace eco en su columna de la existencia de estas posiciones y se distancia de ellas -"La idea de «defensa» del idioma implica la existencia de una «agresión» contra él, esa agresión tantas veces denunciada”-. Pero tampoco están dispuestos a admitirlo todo y el léxico bélico emerge cuando se refieren a neologismos, extranjerismos, tecnicismos y americanismos, al nuevo vocabulario, en definitiva, que conforma el grueso de los enemigos de la lengua, como se ve en 59-64:

59) Los ataques mayores proceden del campo científico (AZV, ROC).

60) un vasto y ambicioso proyecto de defensa de la lengua española. (MS, AyL, $A B C$ ).

61) La idea de «defensa» del idioma implica la existencia de una «agresión» contra él, esa agresión tantas veces denunciada (MS, AyL, $A B C$ ).

62) Se diría que estamos presenciando una desigual batalla entre la lengua y algunos feroces hablantes (MS, AyL, $A B C$ ).

63) está expuesto a agentes corrosivos que es necesario contrarrestar (MS, AyL, $A B C$ ).

64) un programa de combates en todos los frentes donde el idioma sufre asedio (FLC, CFIV, $A B C$ ).

La metáfora "la gestión es una batalla" se complementa con "los neologismos son una catástrofe [natural]” (65-69). Esa sensación de desbordamiento confirma el hecho cierto de la gran renovación del léxico español que se estaba produciendo en los años en los que están escritas estas columnas; pero también es prueba de la percepción tremendista de quienes tenían la tarea de decidir sobre él.

65) Los americanismos están entrando a raudales (AZV, ROC).

66) la irrupción del neologismo (AZV, ROC).

67) en estos tiempos de invasión técnica y anglosajona (AZV, ROC).

68) abundante caudal del español americano (MS, AyL, $A B C$ ).

69) Los tecnicismos, fuente caudalosa de vocablos (FLC, CFIV, ABC). 


\subsubsection{El ejercicio del poder sobre la lengua (II). El estatus religioso de la actividad académica: purificar y bendecir}

En efecto, aunque el análisis de las metáforas sobre la lengua nos ha desvelado un imaginario lingüístico aperturista y conectado con la realidad, el hecho concreto de la gestión de la lengua proporciona otra visión, más conservadora y temerosa, que no escapa a la expresión metafórica de los columnistas académicos. Ante el hecho fáctico de tener que aceptar o no un vocablo, -un neologismo, una acepción inesperada-, los ecos puristas se hacen más evidentes. El purismo, como es sabido, supone un rechazo permanente del cambio (Jernudd y Shapiro 1989; Cameron 1995; Marques 2011), de lo "extraño", como señala Ralph (2000-2001), en el nivel simbólico-cultural. Los columnistas académicos están muy lejos de la exaltación purista de la que hacen gala "guardianes de la lengua" contemporáneos -Luis Calvo, "El Brocense", Carnicer- pero sus metáforas no dejan de ser elocuentes. Algunas de ellas forman parte natural del vocabulario con el que describen su tarea: (70) aclarar, (71) aquilatar, (72) pulimentar, (73) limpiar y (74) dar esplendor, como reza el lema académico:

70) Se han aclarado los significados (AZV, ROC).

71) Los americanismos entran después de haber sido aquilatados (AZV, ROC).

72) Los pulimentos aquí y allá (FLC, CFIV, $A B C$ ).

73) rellene los huecos del registro, lo limpie de antigüedades y localismos, y afronte la incorporación de todo lo nuevo útil (FLC, CFIV, $A B C$ ).

74) falta a su deber de limpiar y por tanto, de dar esplendor (FLC, CFIV, $A B C$ ).

Otras, dejan entrever el miedo a que las nuevas palabras puedan perjudicar al idioma. Abundan entonces las metáforas de la degradación, el deterior y el decaimiento de la lengua -lo contrario de la pureza- como vemos en los ejemplos 75-80, particularmente usados por Lázaro Carreter:

75) la divergente degradación semántica de algunas voces (FLC, CFIV, $A B C$ ).

76) para impedir los descarríos y el deterioro (FLC, CFIV, $A B C$ ).

77) decaimiento acelerado del español (FLC, CFIV, $A B C$ ).

78) Tal vez por los frecuentes contextos lúbricos se había contagiado de ellos (FLC, CFIV, $A B C$ ).

79) Se mantienen estas entradas como principales, ya que las mutiladas se remiten a ellas (FLC, CFIV, $A B C$ ).

80) El diccionario puede acoger voces extranjeras sin maquillarlas.

La tendencia al "higienismo verbal" presente en las columnas académicas se muestra, en términos de Cameron (1995), en el deseo de orden y el temor al desorden que, en el fondo, subyace en los textos.

La metáfora religiosa, por su parte, acaba de reafirmar no solo la mirada sobre la lengua como objeto sagrado -las palabras se consagran (81) o se bautizan (82) sino, en general, la concepción de la actividad académica como alguna forma de acción religiosa. Los columnistas académicos hablan de fe (83), de devotos (84) y 
de devocionario (85) al mencionar el Diccionario, o utilizan terminología religiosa (86-87) -a la que Manuel Seco es bastante asiduo- para referirse a numerosas actividades verbales:

81) Se añadirá, pues, ese valor a los consagrados ya (AZV, ROC).

82) Me pidió que bautizara con un nombre de marca (FLC, CFIV, $A B C$ ).

83) ciudadanos que conservan pura la $f e$ en el Diccionario y en la Academia (MS, AyL, $A B C)$.

84) que muchos devotos seguidores todavía recordamos gratamente (MS, AyL, $A B C$ )

85) Cuántos españoles, ¿cuántas casas españolas tendrán y usarán su «devocionario» del idioma? (MS, AyL, $A B C$ ).

86) esas distinciones son teológicas (MS, AyL, $A B C$ ).

87) incluso el que los puristas dejen de rasgarse las vestiduras por su causa (MS, AyL, $A B C)$.

La sacralización de la lengua es una maniobra de poder que convierte a los académicos en sus "sacerdotes" y que abre paso al premio y al castigo, al pecado y a la culpa, tan frecuentes en la terminología del purismo lingüístico. En los columnistas académicos el tratamiento de lo religioso es, ciertamente, más cercano a un capricho estilístico, pero el hecho de su presencia en textos dirigidos al público propicia su naturalización, contribuye a la "consagración" de la actividad académica y consolida su autoridad ahora también espiritual.

El sentido de lo religioso-verbal se extiende a lo pagano y retoma los mitos de la magia (88) y el misterio (89) de las palabras:

88) Palabrería no exenta de magia (AZV, ROC).

89) vocablo familiar y misterioso (FLC, CFIV, $A B C$ ).

\subsubsection{Sembrar, recoger, aclimatar}

Finalmente, la metáfora "la gestión de la lengua es una actividad agrícola" aunque menos productiva que las anteriores, sirve para mostrar el lenguaje como un espacio fecundo y a sus practicantes y cuidadores como hortelanos encargados del huerto del lenguaje. En 90-96 se muestran algunos ejemplos:

90) Espigando en las enmiendas (AZV, ROC).

91) de voces que han sido recogidas por el habla general media. (AZV, ROC).

92) los cultivadores de nuestras letras (MS, AyL, $A B C$ ).

93) no pocas de estas propuestas logran un arraigo casi simbólico (MS, AyL, $A B C$ ).

94) Hay que sembrar en ellos no sólo el hábito de la lectura (MS, AyL, $A B C$ ).

95) no se acuerda para nada del invernadero en que vivía hace cien años (MS, AyL, $A B C)$.

96) Conecta con una raíz fundamental de nuestro pasado (FLC, CFIV, $A B C$ ). 


\section{Conclusiones: Un Diccionario no debe taparse los ojos ante la realidad}

Las columnas que hemos analizados constituyen un hecho excepcional en el género, pues representan el esfuerzo de comunicación y de conexión con la sociedad que decidió llevar a cabo la Academia en etapas particularmente complejas y con una gran actividad entorno a la lengua. Como una fuerza viva más del país, la Academia percibe la necesidad de renovación, de no quedarse atrás y sale a la luz pública para explicarse. Sus textos van a ofrecer una imagen muy distinta a la de otros columnistas que, en los mismos años, colaboraban en los mismos medios. Si estos recriminan, denuncian, proscriben los malos usos, los académicos informan, describen, dan a conocer la vitalidad de la lengua y la acción de sus gestores. Quieren ofrecer una imagen de dinamismo y de ligazón social y, para ello, se van a valer de un universo metafórico con el que construir una visión de la lengua y de la propia institución. Ciertamente, las metáforas metalingüísticas les permiten proporcionar un escenario explicativo familiar, pues todas pertenecen al patrimonio compartido de usos metafóricos que se reinventan y se focalizan para expresar distintos posicionamientos y una determinada concepción de la lengua. Las metáforas, como señala Hart (2008: 91), tienen un claro componente ideológico pues presentan la realidad organizada según determinados patrones que, añadimos, influyen sin duda en la conciencia metalingüística de los hablantes, en lo que piensan que es bueno para la lengua.

En los textos analizados las metáforas sobre lengua están al servicio de los intereses de los columnistas académicos y así se convierten en una herramienta explicativa para presentar la lengua como un ente dinámico, vivo, en constante proceso de cambio, flexible y valioso. Zamora Vicente, Seco y Lázaro Carreter parecen no querer darle la espalda a la realidad cambiante en la que viven y deciden mostrar una mirada abierta, ligada a los tiempos de transformación, "Los avestruces nunca han sido buenos lexicógrafos", comenta irónicamente Seco. Pero al mismo tiempo, las metáforas les tienden una trampa y su presencia-seguramente a veces inconsciente- al referirse a cualquier aspecto de la gestión de la lengua, descubre una concepción de la labor académica asentada en la autoridad, la normatividad y el purismo. Las metáforas metalingüísticas tienen ahora peso argumental y sirven para sostener y justificar una forma de actuar sobre la lengua profundamente arraigada en la institución. En nuestra opinión, las metáforas sobre la lengua -tal y como proponíamos al principio de este trabajo- contribuyen, en efecto, a transmitir un imaginario sobre la lengua y sobre la Academia. Este es hasta cierto punto contradictorio, pero perfectamente explicable en el contexto de cambio e inestabilidad en el que lengua y sociedad estaban inmersos.

\section{Referencias}

1. Aznárez Mauleón, M. (2006). La fraseología metalingüística con verbos de lengua en español actual. Berlin, Peter Lang

2. Bermel, N (2007). Metaphor and the conceptualization of language. En Bermel, N. Linguistic authority, language ideology, and metaphor: The czech orthography wars (pp. 262-291). Berlin, Mouton de Gruyter. DOI:

https://doi.org/10.1515/9783110197662

3. Caffi, C. (1994). Metapragmatics. En Asher, R. E. (Ed.), Encyclopedia of language and linguistics (pp. 2461-2466). Oxford, Pergamon. DOI: https://doi.org/10.1016/03782166(94)90110-4

4. Cameron, D. (1995). Verbal Hygiene. London, Routledge. 
5. Cellard, K. y Larose, K. (2010). La langue au quotidien. Les intellectuels et le français dans la presse québécoise, anthologie. Vol. 1. Les douaniers de la langue (1874-1957). Québec, Éditions Nota bene.

6. Ciapuscio,G. (2013). Las metáforas en las cartas de lectores de revistas científicas. Rétor. Revista de Retórica, 3(2), pp. 168-176. Recuperado de: http://revistaretor.org/.

7. Del Valle, J. (2011). Panhispanismo e hispanofonía: breve historia de dos ideologías siamesas. Sociolinguistic Studies, 5(3), pp. 465-484.

DOI: https://doi.org/10.1558/sols.v5i3.465

8. Fabré, G. (2012). Des métaphores sur la langue. Note Critique de Cellard-Larose, La langue au quotidien. Recherches sociografiques, LII(1), pp. 201-2012. DOI: https://doi.org/10.7202/1008926ar

9. Fernández Bernárdez, C. (2002). Expresiones metalingüísticas con el verbo 'decir'. A Coruña, Universidade da Coruña.

10. Fernández Marrero, J. J. (1999). Actividad normativa y conciencia lingüística. Técnicas de control de las evaluaciones populares. En Perl, M. y Pörtl, K. (Eds.), Identidad cultural y lingüística en Colombia, Venezuela y en el caribe Hispánico. (pp. 175-186). Tübingen, Max Niemeyer.

11. Goatly, A. (2006). Ideology and Metaphor. English Today, 87(22), 3, pp. 25-38. DOI: https://doi.org/10.1017/S0266078406003051

12. Goatly, A. (2007). Washing the Brain: Metaphor and Hidden Ideology. Amsterdam, John Benjamins Publishing. DOI: https://doi.org/10.1075/dapsac.23

13. Hart, C. (2008). Critical Discourse Analysis and Metaphor: toward a theoretical framework. Critical Discourse Analysis, 5(2), pp. 91-106.

DOI: https://doi.org/10.1080/17405900801990058

14. Jernudd, B. y Shapiro, M. (1989). The politics of language purism. Berlin, Mouton de Gruyter. DOI: https://doi.org/10.1515/9783110868371

15. Lakoff, G. y Johnnson, M. (1995 [1980]). Metáforas de la vida cotidiana, Madrid, Cátedra.

16. Ludwig, R. (2000-2001). Desde el contacto hacia el conflicto lingüístico: el purismo en el español. Concepto, desarrollo histórico y significado actual. BFUCh, XXXVII, pp. 167-196.

17. Manero, E. (2005). Aproximación a un estudio del refrán. El refranero español de contenido metalingüistico. Pamplona, Universidad de Navarra.

18. Marimón Llorca, C. (2018). La Academia española trabaja. Actitudes lingüísticas y estrategias valorativas en las Columnas sobre la Lengua (CSL). Cuadernos ASIPI, 12, pp. 169-190.

19. Marimón Llorca, C. (2019). Las columnas sobre la lengua, entre la norma lingüística y el uso real. En Poch, D. (Ed.), El español de Cataluña en los medios de comunicación (pp. 9-25), Madrid-Frankfurt, Iberoamericana-Vervuert.

20. Marimón Llorca, C. (2021, en prensa). The battle on language revisited. Metalinguistic metaphors in informative speech about feminist language. En Mateo, J. y Yus, F. (Eds.) Metaphor and specialized discourse. Berlin, Peter Lang.

21. Marques, J. G. (2011). Normas linguísticas e purismo: algumas observações críticas. Recorte, 8(1), pp. 1-15.

22. Moreno Cabrera, J. C. (2014). Imágenes y metáforas de la comunicación lingüística. En Tordesillas, M y Suárez, P. (Eds.), Miradas cientificas en torno... al lenguaje: lenguaje, lengua ydiscurso: diálogos internacionales e interdisciplinares (pp. 57-80). Zaragoza, Pórtico.

23. Musci, M. (s.a.). Explicar, identificar, persuadir, confrontar: qué hacen las metáforas en el discurso de la lingüística. Recuperado de:

https://aledar.fl.unc.edu.ar/files/Musci-Monica1.pdf

24. Olza Moreno, I. (2011). Corporalidad y lenguaje: La fraseología somática metalingüistica del español. Berlin, Peter Lang.

25. Rey-Debove, J. (1997). Le Métalangage. Paris, Armand Collin

26. Reyes, G. (2002). Metapragmática: lenguaje sobre lenguaje, ficciones, figuras. Valladolid, Universidad de Valladolid.

27. Rojas, D. y Avilés, T. (2014). Ideologías lingüísticas en la fraseología del español de Chile: dos momentos, una concepción del lenguaje. Onomázein ,29, pp. 64-77. DOI: https://doi.org/10.7764/onomazein.29.3 
28. Santibáñez, C. (2009). Metáforas y argumentación: Lugar y función de las metáforas conceptuales en la actividad argumentativa. Signos, 42(70), pp. 245-269. DOI: https://doi.org/10.4067/S0718-09342009000200005

29. Selden, R. (2010). Historia de la crítica literaria del siglo XX. Del formalismo al postestructuralismo. Madrid, Akal.

30. Silverstein, M. (1993). Metapragmatic discourse and metapragmatic function. En Lucy J. H. (Ed.), Reflexive language. Reported speech and metapragmatics (pp. 33-58). Cambridge, Cambridge University Press.

DOI: https://doi.org/10.1017/CBO9780511621031.004

31. Soriano Salinas, C. (2012). La metáfora conceptual. En Ibarretxe-Antuñano, I. y Valenzuela, J. (Eds.), Lingüistica Cognitiva (pp. 87-109). Barcelona, Anthropos.

32. Spang, K. (1979). Fundamentos de retórica. Pamplona, EUNSA.

33. Spillner, B. (1979). Lingüística y literatura. Madrid, Gredos.

34. Sweetser, E. (1992). English Metaphors for Language: Motivations, Conventions, and Creativity. Poetics Today, 13(4), pp. 705-724. DOI: https://doi.org/10.2307/1773295

35. Underhill, J. (2012). Creating Worldviews. Metaphor, Ideology and Language. Edinburg, University Press.

36. Ungerer, F. \& Schmid, H. J. (1996). An Introduction to Cognitive Linguistics. London, Longman.

37. Van Dijk Teun. A. (2008). Semántica del Discurso e Ideología. Discurso y Sociedad, 21(1), pp. 201-261.

38. Villa, M. E. (2018). Las metáforas en la lingüística. Análisis de algunas conceptualizaciones metafóricas de los fenómenos lingüísticos. Círculo de lingüística aplicada a la comunicación, 73, pp. 303-314.

DOI: https://doi.org/10.5209/CLAC.59071

39. Walsh, O. y Cotelli, S. (2021, en prensa). Les métaphores dans les chroniques de langage en France et en Suisse. En Marimón Llorca, C., Remysen, W. y Rossi F. (Eds.), Le ideologie linguistiche: dibattiti, purismi e strategie discorsive. Frankfurt, Peter Lang. 